\title{
DETECTION OF SUB CLINICAL LEFT VENTRICULAR SYSTOLIC DYSFUNCTION IN DIABETIC PATIENTS WITH DIABETIC RETINOPATHY BY 2D SPECKLE TRACKING ECHOCARDIOGRAPHY
}

By

\author{
Mohammed S. Al-Maghraby*, Abd El-Hamid I. Abd El-Hamid*, Abd \\ EL-Magid M. Tag El-Din**, Abd El-Mohsen M. Abdu*
}

Departments of *Cardiology and **ophthalmology, Faculty of Medicine, Al-Azhar University, Cairo, Egypt

Corresponding author: Mohammed S. Al maghraby, Mobile: (+20) 01095341148,

E-mail: $\underline{\text { m7mdsalah10215@gmail.com }}$

\begin{abstract}
Background: Retinopathy is one of the microvascular complications of DM. In some studies, it has been proposed that diabetic retinopathy might be associated with LV diastolic dysfunction, development of heart failure, and diabetic cardiomyopathy in the future

Objective: To detect subclinical left ventricular Systolic dysfunction by 2D Speckle Tracking Echocardiography in Patients with DM with Diabetic retinopathy and to Correlate between the class of retinopathy and the subclinical systolic dysfunction.

Patients and Methods: Our study comprised 70 patients (31 male \& 39 females) suffering from diabetes mellitus (type I\& type II) were recruited from the endocrinology clinic \& ophthalmology clinic and 30apparently normal people with matched age, sex status as controls (14 males and 16 females). The studied population was classified into two groups: *First group (patient group) consisted of 70 patients with Type I \&II DM \{31 males and 39 females with mean age $46.44 \pm 8.05$ years \& mean duration of diabetes is $13.29 \pm 6.04$ years and mean $\mathrm{HbA1C} 8.63 \pm 1.75$. ${ }^{*}$ Second group (control group) consisted of 30 healthy subjects $\{16$ males and 18 females with mean age $44.30 \pm 7.91$.
\end{abstract}

Results: in comparison with healthy subjects, patients with diabetic retinopathy were found to have lower LV systolic function using 2D speckle tracking. According to LV GLSS\% showed that the mean values were $-14.87 \pm 1.28$ and $-20.62 \pm 1.31$ in the patients and control groups, respectively. They showed highly statistically significant difference between the two groups according to LV GLSS\%. The mean values of the patient subgroups were $-14.87 \pm 1.28$ and $-16.75 \pm 0.75$ in subgroup $\mathrm{R}+\mathrm{VE}$ and $\mathrm{R}-\mathrm{VE}$, respectively. They showed a statistically highly significant difference $(\mathrm{P}<0.001)$.

Conclusion: the 2D speckle tracking method appears to be useful in the detection of LV systolic dysfunction in patients with diabetic retinopathy (one of the microvascular complications of DM). Subclinical left ventricular systolic dysfunction in diabetic patient with diabetic retinopathy is associated with the fact that DM is known to cause the development of heart failure even in the absence of coronary artery disease. The presence of diabetic retinopathy signifies an excess risk of HF, independent of known risk factors. Parameters of LV systolic function were worsened with increasing severity of retinopathy.

Keywords: Subclinical LV dysfunction, 2D speckle tracking echocardiography, diabetic retinopathy. 


\section{INTRODUCTION}

Cardiovascular complications are the leading causes of morbidity and mortality in the diabetes mellitus (DM) population (Maisch et al., 2011).

DM can lead to disharmony in cardiac structures and functions with absence of coronary artery disease and without affecting blood pressure, which is known as diabetic cardiomyopathy (Maisch et al., 2011).

The pathogenesis of diabetic cardiomyopathy is believed to be multifactorial but the exact cause is not known (Maisch et al., 2011).

Impaired cardiac insulin metabolic signaling, mitochondrial dysfunction, increases in oxidative stress, reduced nitric oxide bioavailability, elevations in advanced glycation end products and collagen-based cardiomyocyte and extracellular matrix stiffness, impaired mitochondrial and cardiomyocyte calcium handling, inflammation, reninangiotensin-aldosterone system activation, cardiac autonomic neuropathy, endoplasmic reticulum stress, microvascular dysfunction, and a myriad of cardiac metabolic abnormalities have all been implicated in the development and progression of diabetic cardiomyopathy (Jia et al., 2018).

All these underlying pathogenic conditions change cardiac structure and may lead to cardiac fibrosis.

Echocardiography is a fundamental technique in the diagnosis of diabetic cardiomyopathy. Cardiomyopathy changes in the earlier course of DM are known as a state of preserved LV ejection fraction (LV-EF) with abnormalities in diastolic functions. It is known that LV$\mathrm{EF}$ is not an objective tool in the evaluation of systolic functions. Therefore, subclinical LV systolic dysfunction may not be recognized at that stage (Lee and Kim, 2017).

STE is the procedure of choice, compared with tissue Doppler imaging, because it eliminates angle dependency and the need of high frame rates and allows echocardiographic measurement of radial and circumferential strain. Moreover, when compared with magnetic resonance imaging as a bedside tool, it is a cheap and readily available procedure (Mor-Avi et al., 2011).

Retinopathy is the most frequent and serious complication of DM. It is also among the most important causes of vision loss in people of working age (Sivaprasad et al., 2012).

Retinopathy is one of the microvascular complications of DM. In some studies, it has been proposed that diabetic retinopathy might be associated with LV diastolic dysfunction, development of heart failure, and diabetic cardiomyopathy in the future (Kurioka et al., 2013).

The present study aimed to detect subclinical left ventricular systolic dysfunction by 2D speckle tracking echocardiography in patients with DM with Diabetic retinopathy and to correlate between the class of retinopathy and the subclinical systolic dysfunction.

\section{PATIENTS AND METHODS}

This cross-sectional comparative study involved 70 diabetic patients collected from the Endocrinology and 
ophthalmology clinics of Al-Azhar University Hospitals. The patients were screened for the study enrollment prospectively. The study was performed at Cardiology Department, Faculty of Medicine, Al-Azhar University during the period from October, 2019 to April, 2020.

The protocol and all corresponding documents were approved by Ethical and Research committee, Faculty of Medicine, Al-Azhar University and patients provided informed consents.

The present work studied and evaluated the subclinical left ventricular (LV) systolic dysfunction by 2D speckle tracking echocardiography in all diabetic selected patients and control.

The patients were classified into two groups matched in age:

Group (1): Patients: Seventy patients with diabetes mellitus.

Group (2): Control group: Thirty sex-and age-matched apparently healthy individuals.

\section{Inclusion criteria:}

Patients who were diagnosed as DM according to the definition of a fasting blood glucose of $>126 \mathrm{mg} / \mathrm{dl}$ measured on two different occasions or patients treated with on oral anti diabetic drugs and/or insulin. Patients with DM were divided into two groups according to the findings of the funduscopic examination based on the modified Airlie-House classification (Early Treatment Diabetic Retinopathy Study Research Group (1991), i.e. Patients with retinopathy (proliferative or nonproliferative) and without retinopathy.

\section{Exclusion criteria:}

Documented IHD, patients with congenital heart diseases, Patients with heart failure, patients with atrial fibrillation, end Stage renal disease, Patient refusal, poor acoustic window patients with reduced ejection fraction $\leq$ $50 \%$, significant comorbidities, patients with bad compliance, uncooperative patients, patients that refused the consent or the study or inability to give informed consents.

All patients were subjected to the following:

Complete history, HBA1C, resting surface 12 leads ECG, echocardiography and fundus examination.

\section{Echocardiographic examination:}

All patients were examined at rest in the left lateral decubitus position to obtain adequate images in different standard views.

- Chamber quantification was performed in accordance with the recommendations of the American society of echocardiography and Assessment of the Left Heart in Adults (Marwick, 2006) respectively.

- Left ventricular end diastolic dimension (LVEDD): this will be done using long axis view with M-mode sampling and 2D.

- Left ventricular Ejection fraction (LVEF \%) will be determined using Simpson's biplane volume try.

Two-dimensional Speckle tracking Echocardiography (STE)

Two-dimensional (2D) strain represents myocardial deformation from a 
2D point of view. STE analysis using the commercially available automated function image technique was applied to apical long axis slices (long axis two chamber and four chamber views) for assessment of LV global longitudinal strain (GLS).

The endocardial borders were traced in the end systolic frame of the 2D images from each of the three apical views (each divided into six conventional segments). Speckles were tracked frame by frame throughout the LV wall until the software automatically approved the tracking for the six segments. Segments that failed to track were adjusted manually by the operator until the software approved them. GLS was calculated as the average longitudinal strain of all six segments for each of the three views (two chamber, four chamber and long-axis, i.e. as the mean strain of all 18 segments), GLS reference values was according to Kocabay et al. (2014).

\section{Statistical analysis:}

Data were collected in a master sheet, coded, entered and analyzed using both SPSS version 22 medical statistics software and Microsoft Excel v. 2016.

Quantitative data were expressed as mean \pm standard deviation (SD) and range and compared by independent t-test.

Qualitative data were expressed as frequency and parentage range and compared by Chi-square test

One-way ANOVA with post hoc test: Least Significant Difference (LSD) was used for multiple comparisons

Probability ( $\mathrm{P}$ value): $\mathrm{P}$ value of $<0.05$ indicated significant results, 


\section{RESULTS}

There was no statistically significant difference between control and patient groups according to demographic data. (Table 1).

Table (1): Comparison between patients and control according to demographic data

\begin{tabular}{|c|c|c|c|}
\hline $\begin{array}{l}\text { Groups } \\
\text { Parameters }\end{array}$ & $\begin{array}{c}\text { Control } \\
(n=30)\end{array}$ & $\begin{array}{c}\text { Patient } \\
(\mathrm{n}=70)\end{array}$ & p-value \\
\hline $\begin{array}{l}\text { Sex } \\
\text { Female } \\
\text { Male }\end{array}$ & $\begin{array}{l}16(53.3 \%) \\
14(46.7 \%)\end{array}$ & $\begin{array}{l}39(55.7 \%) \\
31(44.3 \%)\end{array}$ & $>0.05$ \\
\hline $\begin{array}{l}\text { Age (years) } \\
\text { Mean } \pm S D \\
\text { Range }\end{array}$ & $\begin{array}{c}44.30 \pm 7.91 \\
18-55\end{array}$ & $\begin{array}{c}46.44 \pm 8.05 \\
30-59\end{array}$ & $>0.05$ \\
\hline $\begin{array}{l}\text { BMI }\left[\mathbf{w t} /(\mathbf{h t})^{2}\right] \\
\text { Mean } \pm \text { SD } \\
\text { Range }\end{array}$ & $\begin{array}{c}23.57 \pm 2.10 \\
18-29\end{array}$ & $\begin{array}{c}24.46 \pm 2.40 \\
19-30\end{array}$ & $>0.05$ \\
\hline $\begin{array}{l}\text { Smoker } \\
\text { No } \\
\text { Yes }\end{array}$ & $\begin{array}{l}18(60 \%) \\
12(40 \%)\end{array}$ & $\begin{array}{l}45(64.3 \%) \\
25(35.7 \%)\end{array}$ & $>0.05$ \\
\hline
\end{tabular}

There was no statistically significant difference between control and patient

groups according to hemodynamic data except for heart rate. (Table 2).

Table (2): Comparison between patients and control according to hemodynamic data

\begin{tabular}{|c|c|c|c|}
\hline $\begin{array}{l}\text { Groups } \\
\text { Parameters }\end{array}$ & $\begin{array}{c}\text { Control } \\
(n=30)\end{array}$ & $\begin{array}{c}\text { Patient } \\
(n=70)\end{array}$ & p-value \\
\hline $\begin{array}{l}\text { SBP }(\mathbf{m m H g}) \\
\text { Mean } \pm \text { SD } \\
\text { Range }\end{array}$ & $\begin{array}{c}121.00 \pm 6.35 \\
110-130 \\
\end{array}$ & $\begin{array}{c}123.29 \pm 7.84 \\
110-140 \\
\end{array}$ & $>0.05$ \\
\hline $\begin{array}{l}\text { DBP }(\mathbf{m m H g}) \\
\text { Mean } \pm \text { SD } \\
\text { Range } \\
\end{array}$ & $\begin{array}{c}83.33 \pm 8.98 \\
70-100 \\
\end{array}$ & $\begin{array}{c}81.64 \pm 6.85 \\
70-95 \\
\end{array}$ & $>0.05$ \\
\hline $\begin{array}{l}\text { Heart rate } \\
\text { Mean } \pm \text { SD } \\
\text { Range } \\
\end{array}$ & $\begin{array}{c}61.17 \pm 3.90 \\
68-79 \\
\end{array}$ & $\begin{array}{c}59.30 \pm 4.20 \\
54-70 \\
\end{array}$ & $<0.05$ \\
\hline
\end{tabular}

There wasa statistically significant difference between control and patient groups according to Hemoglobin A1C. (Table 3).

Table (3): Comparison between patients and control according to HBA1C

\begin{tabular}{|l|c|c|c|}
\hline Garameters & $\begin{array}{c}\text { Control } \\
(\mathbf{n = 3 0})\end{array}$ & $\begin{array}{c}\text { Patient } \\
(\mathbf{n = 7 0 )}\end{array}$ & p-value \\
\hline HBA1C & $4.75 \pm 0.70$ & $8.62 \pm 1.75$ & $<0.001$ \\
Mean \pm SD & $3.5-6.1$ & $6.5-11.5$ & \\
\hline Range &
\end{tabular}


There was no statistically significant difference between control and patient groups according to conventional echo (Table 4).

Table (4): Comparison between patients and control according to conventional echo

\begin{tabular}{|c|c|c|c|}
\hline $\begin{array}{l}\text { Conventionat } \\
\text { Echo }\end{array}$ & $\begin{array}{l}\text { Control } \\
(n=30)\end{array}$ & $\begin{array}{l}\text { Patient } \\
(\mathrm{n}=70)\end{array}$ & p-value \\
\hline $\begin{array}{l}\text { Aortic Dimensions } \\
\text { Mean } \pm \text { SD } \\
\text { Range } \\
\end{array}$ & $\begin{array}{c}28.20 \pm 3.53 \\
21-34\end{array}$ & $\begin{array}{c}29.51 \pm 3.29 \\
23-39\end{array}$ & $>0.05$ \\
\hline $\begin{array}{l}\text { LAD } \\
\text { Mean } \pm \text { SD } \\
\text { Range } \\
\end{array}$ & $\begin{array}{c}35.57 \pm 6.02 \\
26-56\end{array}$ & $\begin{array}{c}37.21 \pm 3.63 \\
27-42\end{array}$ & $>0.05$ \\
\hline $\begin{array}{l}\text { LV EDD } \\
\text { Mean } \pm \text { SD } \\
\text { Range }\end{array}$ & $\begin{array}{c}48.81 \pm 5.01 \\
40-54.2\end{array}$ & $\begin{array}{c}51.01 \pm 6.99 \\
40-58\end{array}$ & $>0.05$ \\
\hline $\begin{array}{l}\text { LV ESD } \\
\text { Mean } \pm \text { SD } \\
\text { Range }\end{array}$ & $\begin{array}{c}31.33 \pm 4.83 \\
24-34.9\end{array}$ & $\begin{array}{c}33.26 \pm 5.25 \\
24-45\end{array}$ & $>0.05$ \\
\hline $\begin{array}{l}\text { LVEDV } \\
\text { Mean } \pm \text { SD } \\
\text { Range }\end{array}$ & $\begin{array}{c}107.70 \pm 12.25 \\
80-145\end{array}$ & $\begin{array}{c}110.23 \pm 13.39 \\
94-153\end{array}$ & $>0.05$ \\
\hline $\begin{array}{l}\text { LVESV } \\
\text { Mean } \pm S D \\
\text { Range } \\
\end{array}$ & $\begin{array}{c}46.10 \pm 8.25 \\
29-57 \\
\end{array}$ & $\begin{array}{c}43.07 \pm 7.57 \\
31-56 \\
\end{array}$ & $>0.05$ \\
\hline $\begin{array}{l}\text { LVEF } \\
\text { Mean } \pm \text { SD } \\
\text { Range }\end{array}$ & $\begin{array}{c}57.51 \pm 4.61 \\
50.3-68.2\end{array}$ & $\begin{array}{c}59.77 \pm 6.62 \\
50-72\end{array}$ & $>0.05$ \\
\hline
\end{tabular}

There was a statistically significant difference between control and patient groups according to speckle. (Table 5).

Table (5): Comparison between patients and control according to speckle

\begin{tabular}{|l|c|c|c|}
\hline Speckle & $\begin{array}{c}\text { Control } \\
(\mathbf{n = 3 0})\end{array}$ & $\begin{array}{c}\text { Patient } \\
(\mathbf{n = 7 0})\end{array}$ & p-value \\
\hline AP3\% & $-20.47 \pm 1.57$ & $-16.54 \pm 2.28$ & $<0.001$ \\
Mean \pm SD & $-23--17$ & $-23--12.5$ & \\
Range & $-20.37 \pm 1.43$ & $-16.87 \pm 5.02$ & $<0.001$ \\
AP2\% & $-23--18$ & $-23--20$ & \\
Mean \pm SD & $-20.83 \pm 1.66$ & $-17.38 \pm 2.22$ & $<0.001$ \\
Range & $-24--18$ & $-22--13$ & \\
AP4\% & & & $<0.001$ \\
Mean $\pm S D$ & $-20.62 \pm 1.31$ & $-16.92 \pm 2.23$ & \\
Range & $-23--18$ & $-22--13$ & \\
\hline LV GLSS\% & & & \\
Mean $\pm S D$ & &
\end{tabular}

There was a statistically significant difference between retinopathy positive (+ve) and retinopathy negative (-ve) groups according to disease of duration, HbA1C, insulin use and oral anti diabetic. (Table 6). 
Table (6): Comparison between patients and control according to Retinopathy +ve and Retinopathy -ve according to disease of duration, HbA1C, insulin use and oral anti diabetic

\begin{tabular}{|l|c|c|c|}
\hline Fundus exam & R+ve $(\mathbf{n}=\mathbf{4 3})$ & R-ve $(\mathbf{n = 2 7})$ & P value \\
\hline Disease of duration & $17.28 \pm 3.87$ & $6.93 \pm 2.07$ & $<0.001$ \\
\hline HbA1C & $9.65 \pm 1.28$ & $6.99 \pm 1.00$ & $<0.001$ \\
\hline Insulin use & $36(83.7 \%)$ & $3(11.1 \%)$ & $<0.001$ \\
\hline Oral Anti Diabetic & $7(16.3 \%)$ & $24(88.9 \%)$ & $<0.001$ \\
\hline
\end{tabular}

There was statistically significant difference between patient (Retinopathy

+ve and Retinopathy -ve) and control groups according to speckle. (Table 7).

Table (7): Comparison between patients and control according to Retinopathy +ve and Retinopathy -ve and control according to speckle

\begin{tabular}{|l|c|c|c|c|}
\hline Fundus Exam & $\begin{array}{c}\text { Control } \\
(\mathbf{n}=\mathbf{3 0})\end{array}$ & R+ve $(\mathbf{n}=\mathbf{4 3})$ & R-ve $(\mathbf{n}=\mathbf{2 7})$ & P value \\
\hline AP3\% & $-20.47 \pm 1.57$ & $-15.24 \pm 1.57$ & $-18.59 \pm 1.62$ & $<0.001$ \\
\hline AP2\% & $-20.37 \pm 1.43$ & $-16.06 \pm 1.56$ & $-18.17 \pm 7.75$ & $<0.001$ \\
\hline AP4\% & $-20.83 \pm 1.66$ & $-16.04 \pm 1.52$ & $-19.52 \pm 1.25$ & $<0.001$ \\
\hline LV GLSS\% & $-20.62 \pm 1.31$ & $-15.57 \pm 1.44$ & $-19.07 \pm 1.44$ & $<0.001$ \\
\hline
\end{tabular}

There was statistically significant group according to LV GLSS\%, while decrease mean of retinopathy +ve (proliferative $\mathrm{R}$ and non-proliferative 2D LVEF\% insignificant difference. R) subgroups compared to control (Table 8).

Table (8): Comparison between proliferative $R \&$ non proliferative $R$ compared to control group according to LV GLSS\%,2D LVEF\%

\begin{tabular}{|l|c|c|c|c|}
\hline Class of Retinopathy & $\begin{array}{c}\text { Control } \\
(\mathbf{n = 3 0})\end{array}$ & $\begin{array}{c}\text { Proliferative } \\
\text { Retinopathy } \\
(\mathbf{n = 2 7})\end{array}$ & $\begin{array}{c}\text { Non } \\
\text { proliferative } \\
\text { Retinopathy } \\
(\mathbf{n = 1 6})\end{array}$ & p-value \\
\hline LV GLSS\% & $-20.62 \pm 1.31$ & $-14.87 \pm 1.28 \mathrm{a}$ & $-16.75 \pm 0.75 \mathrm{~b}$ & $<0.001$ \\
\hline 2D LVEF\% & $57.51 \pm 4.61$ & $58.37 \pm 5.77$ & $57.59 \pm 4.10$ & $>0.05$ \\
\hline
\end{tabular}

a: significant difference with control, b: significant difference with proliferative retinopathy

There was a statistically significant difference between patient retinopathy +ve (proliferative $\mathrm{R}$ and non-proliferative R) subgroups according to Disease of duration, HbA1Caccording to Disease of duration, HbA1C, while Insulin use and Oral Anti Diabetic insignificant in patients' group. (Table 9). 
Table (9): Comparison between proliferative $\mathbf{R}$ and non-proliferative $\mathbf{R}$ according to Disease of duration, HbA1C, Insulin use, Oral Anti Diabetic

\begin{tabular}{|l|c|c|c|}
\hline parameter & $\begin{array}{c}\text { Proliferative } \\
\text { Retinopathy } \\
(\mathbf{n = 2 7})\end{array}$ & $\begin{array}{c}\text { Non-Proliferative } \\
\text { Retinopathy } \\
(\mathbf{n = 1 6 )}\end{array}$ & p-value \\
\hline Disease of duration & $18.81 \pm 3.53$ & $14.69 \pm 2.98$ & $<0.001$ \\
\hline HbA1C & $10.07 \pm 1.24$ & $8.96 \pm 1.06$ & $<0.005$ \\
\hline Insulin use & $23(85.2 \%)$ & $13(81.3 \%)$ & \\
Oral Anti Diabetic & $4(14.8 \%)$ & $3(18.8 \%)$ & $>0.05$ \\
\hline
\end{tabular}

\section{DISCUSSION}

Our study showed no statistically significant difference between the two groups in terms of Age, sex and smoking. As expected, there was a statistically significant difference in DM and DM retinopathy between the two groups. This is in conformity with the findings of (Karagöz et al., 2015).

There was a statistically significant difference between the two groups in terms of Heart Rate. This was confirmatory to Poanta et al. (2010) in their study of 58 subjects found that cardiac autonomic neuropathy was associated with LV diastolic dysfunction in patients with type $2 \mathrm{DM}$, but without clinical manifestation of the heart disease.

Our study found a statistically significant lower global longitudinal strain by $2 \mathrm{D}$ speckle tracking in $\mathrm{DM}$ group in comparison to the control. This was similar to the findings of Labombarda et al. (2014) who found that GLS was significantly lower in the diabetes vs. control group.

On the contrary, Hensel et al. (2016) noticed that a paradoxical increase of myocardial performance may occur very early in DM as a sign of impaired mechanical efficiency, this difference could be due to ethnic or geographic differences between the studied group or possibly sample size and the duration of the disease.

There was a statistically significant difference in GLS by 2D STE between the groups with DM retinopathy in comparison with the group with no retinopathy. This finding is similar to Walraven et al. (2014) that noticed that there is association between retinopathy and reduced LV EF. Also, it is concordant with Kurioka et al. (2013) that concluded that diabetic retinopathy might be associated with LV diastolic dysfunction, development of heart failure, and diabetic cardiomyopathy after that.

However, it is disconcordant with the result of Karagöz et al. (2015) that concluded that diabetic patients were found to have lower longitudinal myo $\neg$ cardial mechanics compared with healthy control group, unrelated to the presence of retinopathy. This may be due to ethnic or geographic differences among the studied population.

Our study found that the developing of retinopathy is related to the duration of the disease, HbA1C level there was a significant correlation between the presence of retinopathy and duration of the disease\& HbA1C level ( $p$ value $(<0.001,0.005))$. It coincides with Patil et al. (2011) who concluded that diabetic 
patients with retinopathy had higher incidence of LV diastolic dysfunction and it correlated with the duration of diabetes mellitus and $\mathrm{HbA} 1 \mathrm{C}$ level in the study subject.

Our study found that the higher grades of retinopathy(proliferative) is associated with higher affection Of LV systolic function assessed by GLS.It is concordant with the result of Aguilar et al. (2009) and Bhargavi (2013) where parameters of LV systolic function were worsened with increasing severity of retinopathy. It also suggested that retinopathy in an individual with type 2 diabetes mellitus should trigger consideration of further cardiac assessment.

\section{CONCLUSION}

The 2D strain method appears to be useful in the detection of LV systolic dysfunction in diabetic patients with diabetic retinopathy. Subclinical left ventricular systolic dysfunction in diabetic patients with diabetic retinopathy is significantly noticed in comparison with those without retinopathy, also, the proliferative retinopathy is associated with markedly affection of LV systolic function comparing with non-proliferative type. Diabetic patients who are detected with retinopathy should also be assessed for asymptomatic cardiac involvement. However, there must be studies with a larger sample size and follow up period to know the natural history of cardiac involvement in diabetic patients and trial studied to detect the benefit for cardiac screening in such individuals, before strong recommendations are suggested.

\section{REFERENCES}

1. Aguilar, D., Hallman, D. M., Piller, L. B., Klein, B. E. K., Klein, R., Devereux, R. B. and Hanis, C. L. (2009): Adverse association between diabetic retinopathy and cardiac structure and function. American Heart Journal, 157(3): 563-568.

2. Bhargavi, K. (2013): Comparative study of Left Ventricular Function by Echocardiography in Type 2 Diabetes Mellitus Patients with and Without Retinopathy (Doctoral dissertation, Stanley Medical College, Chennai).

3. Early Treatment Diabetic Retinopathy Study Research Group (1991): Grading diabetic retinopathy from stereoscopic color fundus photographs - an extension of the modified Airlie House classification.ETDRS report number 10. Ophthalmology 98(5 Suppl):786-806.

4. Hensel, K. O., Grimmer, F., Roskopf, M., Jenke, A. C., Wirth, S., and Heusch, A. (2016): Subclinical alterations of cardiac mechanics present early in the course of pediatric type 1 diabetes mellitus: A prospective blinded speckle tracking stress echocardiography study. Journal of Diabetes Research, 2016.

5. Jia, G., Hill, M. A. and Sowers, J. R. (2018): Diabetic cardiomyopathy: an update of mechanisms contributing to this clinical entity. Circulation Research, 122(4): 624638.

6. Karagöz, A., Bezgin, T., Kutlutürk, I., Külahçıŏ̆lu, S., Tanboğa, I. H., Güler, A. and Kırma, C. (2015): Subclinical left ventricular systolic dysfunction in diabetic patients and its association with retinopathy: A 2D speckle tracking echocardiography study. Herz, 40(July), 240-246.

7. Kocabay G, Muraru D and Peluso D. (2014): Normal left ventricular mechanics by two-dimensional speckle tracking echocardiography. Reference values in healthy adults. Rev EspCardiol. (Engl Ed), 67:651- 658 .

8. Kurioka $S$, Ose $H$, Fukuma $K$ and Yoshimoto K (2013): Severity of diabetic retinopathy is associated with left ventricular diastolic dysfunction in patients with type 2 diabetes. Diabetes Res Clin Pract.,99(3):287-291. 
9. Labombarda, F., Leport, M., Morello, R., Ribault, V., Kauffman, D., Brouard, J. and Saloux, E. (2014): Longitudinal left ventricular strain impairment in type 1 diabetes children and adolescents: a 2D speckle strain imaging study. Diabetes \& Metabolism, 40(4):292-298.

10. Lee, W. S. and Kim, J. (2017): Diabetic cardiomyopathy: where we are and where we are going. The Korean journal of internal medicine, 32(3): 404.

11. Maisch, B., Alter, P. and Pankuweit, S. (2011): Diabetic cardiomyopathy-fact or fiction? Herz, 36(2): 102-115.

12. Marwick, T. H. (2006): Measurement of strain and strain rate by echocardiography: ready for prime time? Journal of the American College of Cardiology, 47(7): 1313-1327.

13. Mor-Avi, V., Lang, R. M., Badano, L. P., Belohlavek, M., Cardim, N. M., Derumeaux, G. and Sicari, R. (2011): Current and evolving echocardiographic techniques for the quantitative evaluation of cardiac mechanics: ASE/EAE consensus statement on methodology and indications endorsed by the Japanese Society of Echocardiography. European Journal of Echocardiography, 12(3): 167-205.

14. Patil, V. C., Shah, K. B., Vasani, J. D., Shetty, P. and Patil, H. V. (2011): Diastolic dysfunction in asymptomatic type 2 diabetes mellitus with normal systolic function.
Journal of Cardiovascular Disease Research, 2(4):213-222.

15. Poantă, L., Fodor, D. and Albu, A. (2010): Left ventricular function in patients with uncomplicated well-controlled diabetes mellitus. Medical ultrasonography, 12(3): 184-187.

16. Sivaprasad S, Gupta B, Crosby-Nwaobi R and Evans J (2012): Prevalence of diabetic retinopathy in various ethnic groups: a worldwide perspective. SurvOphthalmol 57(4):347-370.

17. Walraven, I., Van den Hurk, K., Van't Riet, E., Kamp, O., Schalkwijk, C. G., Stehouwer, C. D. and Nijpels, G. (2014): Low-grade inflammation and endothelial dysfunction explain the association between retinopathy and left ventricular ejection fraction in men: an 8-year follow-up of the Hoorn Study. Journal of Diabetes and its complications, 28(6): 819-823.

18. Zhu, X. R., Zhang, Y. P., Bai, L., Zhang, X. L., Zhou, J. B. and Yang, J. K. (2017): Prediction of risk of diabetic retinopathy for all-cause mortality, stroke and heart failure Evidence from epidemiological observational studies. Medicine (United States), 96, NO.3. 


\section{إكتشاف الإعتلال الوظيفي للبطين الأيسر في مرضي البول

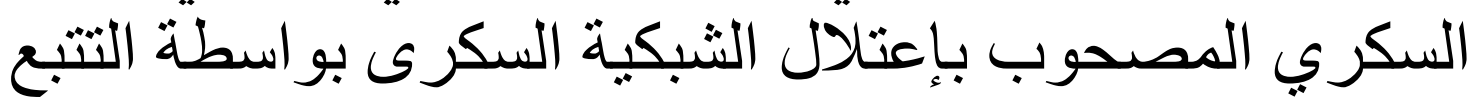 النقطي بالموجات فوق الصوتية ثنائية الأبعاد}

محمد صلاح المغربي، عبد الحميد اسماعيل عبد الحميد، عبد المجيد تاج الدين، عبدالمحسن مصطقى عبده

قسم القلب، قسم الرمد، كلية الطب، جامعة الأزهر

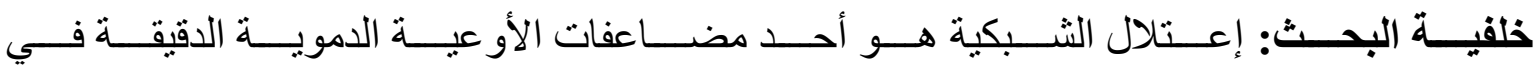

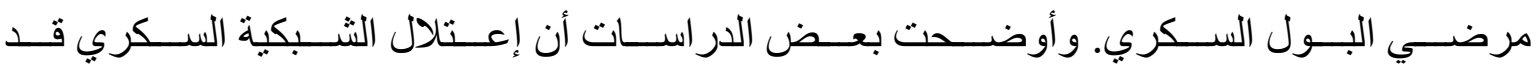

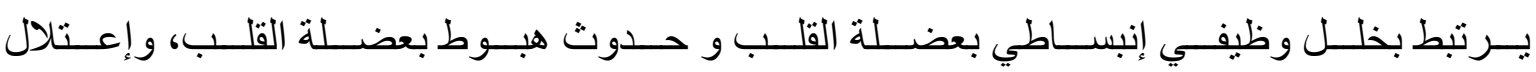
عضلة القلب السكري بعد ذلك.

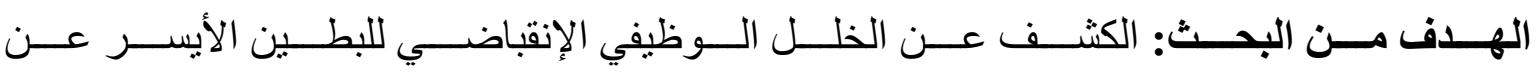

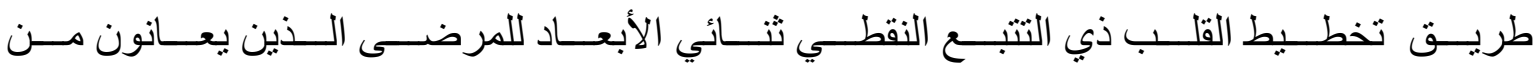

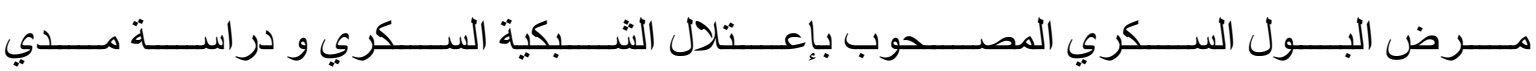
الإرتباط بين درجة إعتلال الثبكية والخلل الوظيفي الإنقباضي لعضلة القلب.

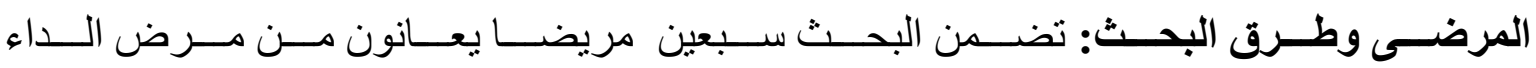

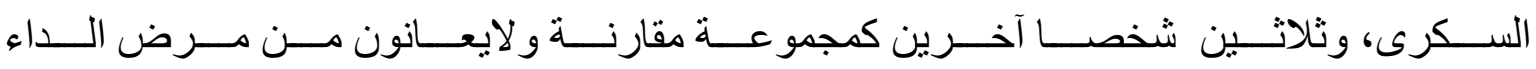

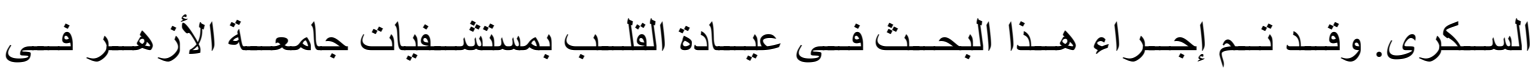

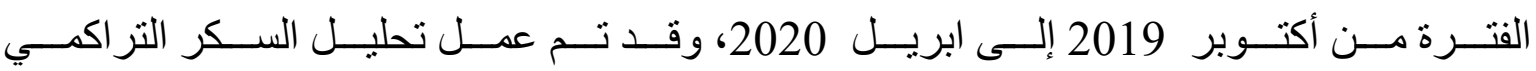

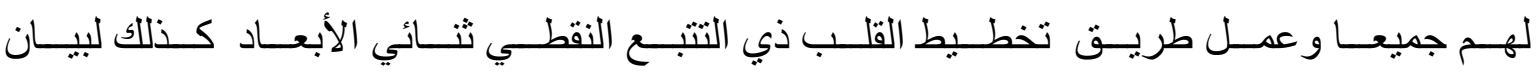

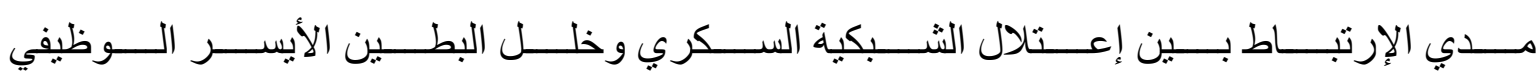
الانقباضي.

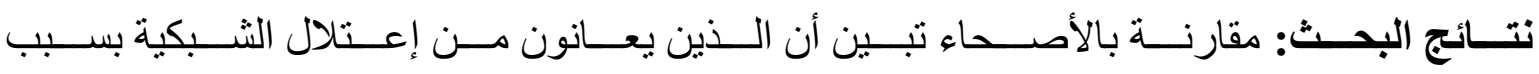

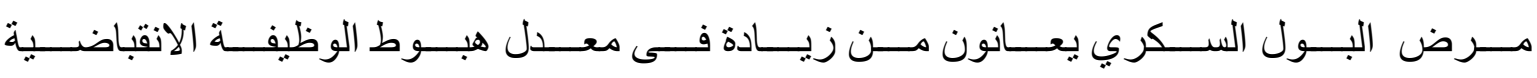
للابطين الأيسر وتناسب ذللك طرديا مع زيادة شدة إعتلال الثبكية. 


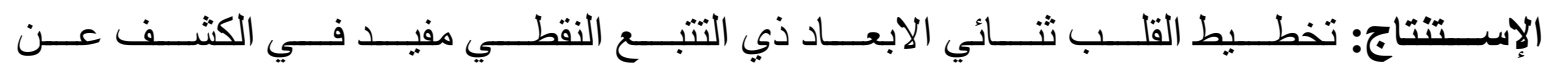

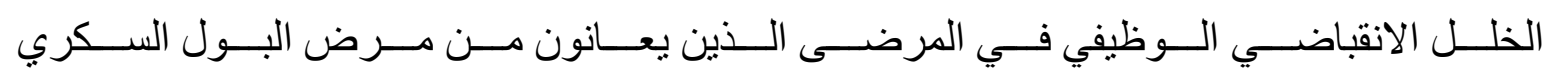

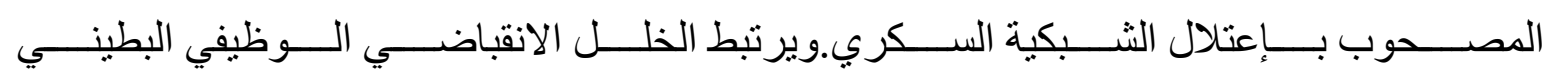

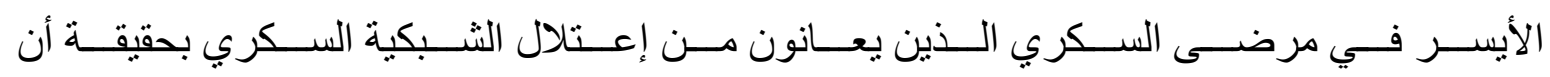

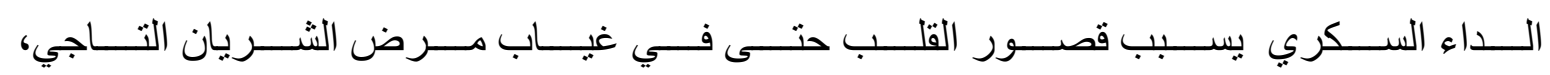

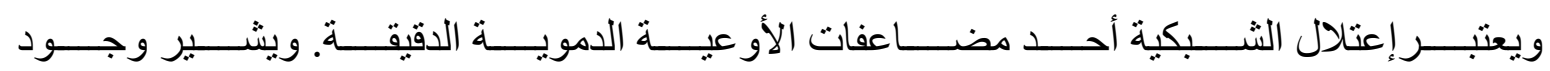

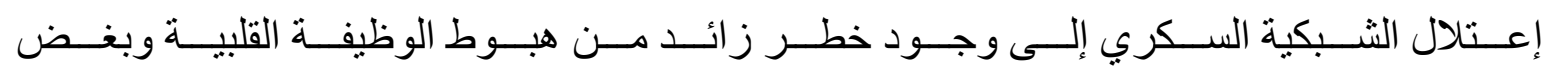

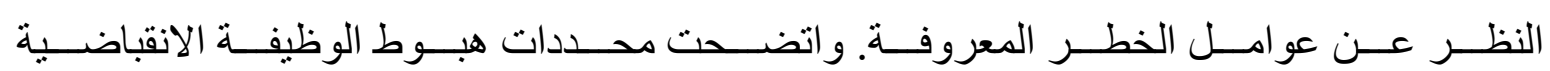
للبطين الأيسر مع زيادة شدة إعتلال الثبكية. 